\title{
Effects of habitual smoking on cardiopulmonary function in taekwondo athletes
}

\author{
Dong-Jin Jang' ', Hee-Cheol Kim', Jae-Kyung Kim', Sun-Young Jung², Dae-Young Kim¹,3* \\ ${ }^{1}$ Institute of Digital Anti-aging Healthcare (IDA), Inje University, Gimhae, Korea \\ 2Department of Physical Therapy, Hosan University, Gyeongsan, Korea \\ ${ }^{3}$ Department of Sports Healthcare, College of Humanities \& Social Sciences, Inje University, Gimhae, Korea
}

This study aimed to verify habitual smoking effects on cardiopulmonary function in taekwondo athletes. Subjects were university taekwondo athletes aged 20-24 years in nonsmoker $(n=9)$ and smoker $(n=6)$ groups. Subjects underwent an exercise examination for their ventilation threshold, minute ventilation, oxygen uptake, maximum volume of minute oxygen consumption, heart rate, and oxygen pulse during exercise and 1,3, and 5 min after maximum exercise. The time of reaching the ventilation threshold was significantly higher in nonsmokers than in smokers. Heart rate during recovery after maximum exercise was significantly lower in nonsmokers for 1 and 3 min. Nonsmokers had significantly higher time for reaching the ventilation threshold and heart rate recovery at 1 and 3 min after exercise. The higher timing of accumulation fatigue in ventilation amount and faster recovery after exercise are useful in continuous exercise and improving athletic performance. Thus, athletes should stop smoking as soon as possible to improve their aerobic physical fitness and athletic performance.

Keywords: Taekwondo athletes, Cardiopulmonary function, Smoking

\section{INTRODUCTION}

The World Health Organization has predicted that more than 10 million people will die by smoking in 2020 due to the continuous growth of the smoking rate (World Health Organization, 1998). Smoking is so detrimental to health that the U.S. Food and Drug Administration has classified cigarettes as a drug. Smoking causes $90 \%$ of death by chronic obstructive pulmonary disease, and increases the risk rate of coronary heart disease by 4 times (Dogan et al., 2011).

Carbon monoxide is 250 times stronger in its affinity to hemoglobin than oxygen, lowering the oxygen saturation of arterial blood $\left(\mathrm{SaO}_{2}\right)$ and the body's ability to utilize oxygen. Moreover, tar stimulates mucus in the airway and induces bronchial tube contraction, increasing airway resistance. This increased airway resistance due to smoking then reduces forced vital capacity and forced expiratory volume in one second and increases the oxygen usage through respiratory muscles, burdening the heart (Tantisu- wat and Thaveeratitham, 2014). The increase of carboxyhemoglobin and reduction of $\% \mathrm{SaO}_{2}$ lowers the timing of the ventilation threshold, which lowers the oxygen transport ability (Anton et al., 2006). To compensate for the reduced $\% \mathrm{SaO}_{2}$, the body temporarily activates the sympathetic nerve activity to increase the heart rate (HR) and cardiac output (CO) to replenish the lack of oxygen, which puts a burden on the heart (Grover et al., 1986; Halliwill and Minson, 2002). The increase of blood pressure during exercise is a CO increase from stroke volume (SV) and HR increase when the volume of maximal oxygen uptake $\left(\mathrm{VO}_{2 \max }\right)$ is $40 \%$ $60 \%$. At an intensity of $60 \%$ or higher, the SV shows a plateauing phenomenon, resulting in the increase of $\mathrm{CO}$ from a linear increase of HR (Grover et al., 1986). Ultimately, smoking reduces respiratory ability and lowers cardiopulmonary functions, indicating that it may be an important factor in reducing the ability to perform exercises (Willemse et al., 2004).

Cardiopulmonary function is an indicator of oxygen supply transport ability to the active muscles for taekwondo athletes who
*Corresponding author: Dae-Young Kim (i] https://orcid.org/0000-0002-4662-4463 Department of Sports Healthcare, College of Humanities \& Social Sciences, Inje University, 197 Inje-ro, Gimhae 50834, Korea

Tel: +82-55-320-3171, Fax: +82-55-320-3545, E-mail: cdps21@inje.ac.kr

Received: November 3, 2017 / Accepted: December 4, 2017
This is an Open Access article distributed under the terms of the Creative Commons Attribution Non-Commercial License (http://creativecommons.org/licenses/by-nc/4.0/) which permits unrestricted non-commercial use, distribution, and reproduction in any medium, provided the original work is properly cited. 
perform high-intensity movements in short periods of time, and it is an important factor that directly affects athletic performance (Seo et al., 2011). Cardiopulmonary function is a term that can be used mixed with cardiopulmonary endurance or cardiorespiratory fitness and indicates the $\mathrm{VO}_{2 \max }$ or ability of aerobic exercises (American College of Sports Medicine [ACSM], 2010). A taekwondo game is composed of three 2-min rounds, and the athletes run about six games on average from preliminary to final rounds when participating in a competition. As they go up into higher rounds, the athletes face stronger competitors and accumulate quite significant metabolic fatigue substance. Taekwondo games are conducted at an average of $85 \%-95 \%$ intensity of maximal heart rate $\left(\mathrm{HR}_{\max }\right)$ from the 1 st to $3 \mathrm{rd}$ round, so high cardiopulmonary fitness and recovery abilities have strong impact on the games. Thus, this research aims to verify the effects of habitual smoking on cardiopulmonary function in taekwondo athletes.

\section{MATERIALS AND METHODS}

\section{Subjects}

The 15 research subjects were 20- to 24-year-old physically healthy university taekwondo athletes without medical conditions. The nonsmoker group ( $\mathrm{n}=9$ ) comprised athletes who had no smoking history at all, and the smoker group $(\mathrm{n}=6)$ comprised those who had smoked at least five cigarettes a day for at least 24 months. All subjects were given sufficient explanations of the content and purpose of the study, then completed forms to provide consent before participating in the experiment.

\section{Measurement of body composition}

The subjects' basic physical characteristics were measured using the automatic height estimator (DS-102, Jenix, Seoul, Korea) for their height $(\mathrm{cm})$ and weight $(\mathrm{kg})$ to calculate their body mass index (BMI) with the calculation BMI $=$ weight $(\mathrm{kg}) /$ height $(\mathrm{m})^{2}$. The body fat percentage was analyzed using the body fat estima-

Table 1. Physical characteristics of the study subjects

\begin{tabular}{lcr}
\hline Variable & Nonsmokers & Smokers \\
\hline Age $(\mathrm{yr})$ & $22.4 \pm 1.3$ & $23.0 \pm 1.4$ \\
Height $(\mathrm{cm})$ & $175.9 \pm 3.3$ & $176.3 \pm 3.4$ \\
Weight $(\mathrm{kg})$ & $71.1 \pm 5.3$ & $73.9 \pm 4.2$ \\
Body mass index $\left(\mathrm{kg} / \mathrm{m}^{2}\right)$ & $22.9 \pm 1.2$ & $23.7 \pm 0.7$ \\
Body fat $(\%)$ & $19.9 \pm 3.1$ & $20.5 \pm 2.4$ \\
Smoking period $(\mathrm{mo})$ & - & $34.5 \pm 8.9$ \\
\hline
\end{tabular}

Values are presented as mean \pm standard deviation. tor (InBody 4.0, Biospace, Seoul, Korea), which uses the bioelectrical resistance method. The physical characteristics of the subjects in each group are shown in Table 1.

\section{Cardiopulmonary function exercise testing}

The exercise testing was continuously measured through minute ventilation (VE), oxygen uptake $\left(\mathrm{VO}_{2}\right), \mathrm{VO}_{2 \max }, \mathrm{HR}$, and oxygen pulse $\left(\mathrm{O}_{2}\right.$ pulse) during exercise and recovery at 1,3 , and 5 min. The exercise examination was estimated using the treadmill and the metabolic gas analyzer system (Quark b2 ${ }^{2}$ Cosmed, Italy). For the exercise examination protocol, Bruce was used to conduct maximum exercise examinations. The maximum competence reaching time standards were set based on the American College of Sports Medicine (ACSM) guideline (2010) for respiratory exchange ratio at 1.15 or higher, rating scales of perceived exertion at 17 or higher, when $\mathrm{VO}_{2}$ value does not increase even when exercise intensity increases, and when the subject requests to stop.

The $\mathrm{O}_{2}$ pulse was calculated by dividing the oxygen intake amount by $\mathrm{HR}$ during exercise examination and recovery $\left(\mathrm{O}_{2}\right.$ pulse $=\mathrm{VO}_{2} /$ HR). For recovery after the end of exercise, the subjects walked lightly (speed, $1.3 \mathrm{mph}$; inclination, 0\%) for about $30 \mathrm{sec}$ immediately after the exercise, and their breathing and HR recovery statuses were observed while they sat in a chair for 5 min after the treadmill had completely stopped. The "modified v-slope" method was utilized to determine the ventilatory threshold (VT). In other words, the VT was determined to be the time of nonlinear increase of carbon dioxide emission amount compared to the oxygen consumption amount $\left(\mathrm{VO}_{2}\right)$ during exercise.

Table 2. Comparison of aerobic fitness variables at the ventilatory threshold (VT) and maximum exercise

\begin{tabular}{|c|c|c|}
\hline Variable & Nonsmokers & Smokers \\
\hline $\mathrm{VE}_{\mathrm{vv}}(\mathrm{L} / \mathrm{min})$ & $71.3 \pm 7.0$ & $67.4 \pm 6.5$ \\
\hline $\mathrm{VO}_{2 \mathrm{vt}}(\mathrm{mL} / \mathrm{kg} / \mathrm{min})$ & $43.8 \pm 5.9$ & $42.0 \pm 4.2$ \\
\hline$H R_{v t}(b p m)$ & $141.7 \pm 7.7$ & $139.3 \pm 7.4$ \\
\hline$R_{v t}(\sec )$ & $526.1 \pm 37.8$ & $469.5 \pm 58.8^{*}$ \\
\hline $\mathrm{VE}_{\max }(\mathrm{L} / \mathrm{min})$ & $132.5 \pm 10.9$ & $128.7 \pm 10.6$ \\
\hline $\mathrm{VO}_{2 \max }(\mathrm{mL} / \mathrm{kg} / \mathrm{min})$ & $62.23 \pm 6.1$ & $58.4 \pm 10.0$ \\
\hline $\mathrm{METs}\left(\mathrm{VO}_{2 \max } / 3.5\right)$ & $16.5 \pm 1.55$ & $16.5 \pm 1.55$ \\
\hline$H R_{\text {max }}(b p m)$ & $184.3 \pm 4.2$ & $182.5 \pm 2.8$ \\
\hline $\mathrm{O}_{2}$ pulse $(\mathrm{mL} / \mathrm{bpm})$ & $24.6 \pm 2.7$ & $23.6 \pm 4.0$ \\
\hline Total exercise time (sec) & $871.1 \pm 75.0$ & $859.1 \pm 58.0$ \\
\hline
\end{tabular}

Values are presented as mean \pm standard deviation.

$V E_{v t}$ values of ventilation at $V_{T} ; \mathrm{VO}_{2 v t}$ oxygen uptake at $\mathrm{VT} ; \mathrm{HR}_{\mathrm{vt}}$, heart rate at $\mathrm{VT}$; $R_{v t}$, reaching time of $\mathrm{VT}$; $\mathrm{V}_{\max }$, maximal ventilation; $\mathrm{VO}_{2 \max }$, maximal oxygen uptake; METs, metabolic equivalent; $\mathrm{HR}_{\max }$, maximal heart rate; $\mathrm{O}_{2}$ pulse, $\mathrm{VO}_{2} / \mathrm{HR}$. ${ }^{*} P<0.05$, independent $t$-test. 
Table 3. Comparison of respiratory variables and heart rate recovery rate at the time of recovery

\begin{tabular}{|c|c|c|c|c|c|c|}
\hline \multirow{2}{*}{ Variable } & \multicolumn{2}{|c|}{$1 \mathrm{Min}$} & \multicolumn{2}{|c|}{$3 \mathrm{Min}$} & \multicolumn{2}{|c|}{$5 \mathrm{Min}$} \\
\hline & Nonsmokers & Smokers & Nonsmokers & Smokers & Nonsmokers & Smokers \\
\hline $\mathrm{VE}(\mathrm{L} / \mathrm{min})$ & $81.4 \pm 18.5$ & $93.7 \pm 8.3$ & $42.2 \pm 5.7$ & $45.0 \pm 3.5$ & $32.9 \pm 3.6$ & $36.7 \pm 5.3$ \\
\hline Decreasing rate $(\Delta \%)$ & $-37.3 \pm 19.1$ & $-26.7 \pm 9.3$ & $-46.9 \pm 7.5$ & $-51.8 \pm 3.4$ & $-21.1 \pm 9.5$ & $-18.4 \pm 10.2$ \\
\hline $\mathrm{VO}_{2 \max }(\mathrm{mL} / \mathrm{kg} / \mathrm{min})$ & $38.6 \pm 6.5$ & $40.9 \pm 8.1$ & $12.8 \pm 1.5$ & $13.9 \pm 1.2$ & $10.6 \pm 1.4$ & $11.8 \pm 1.6$ \\
\hline$\Delta \%$ & $-36.9 \pm 14.9$ & $-29.7 \pm 9.5$ & $-66.0 \pm 5.5$ & $-65.0 \pm 6.4$ & $-16.3 \pm 14.7$ & $-14.6 \pm 12.1$ \\
\hline $\mathrm{HR}$ (bpm) & $136.6 \pm 17.1$ & $155.1 \pm 7.5^{*}$ & $106.2 \pm 7.4$ & $117.8 \pm 7.7^{*}$ & $97.1 \pm 4.8$ & $104.6 \pm 10.5$ \\
\hline$\Delta \%$ & $-25.7 \pm 10.4$ & $-14.9 \pm 4.8^{*}$ & $-21.7 \pm 4.6$ & $-24.0 \pm 3.6$ & $-8.4 \pm 4.8$ & $-10.5 \pm 13.0$ \\
\hline $\mathrm{O}_{2}$ pulse (mL/bpm) & $15.2 \pm 4.5$ & $17.8 \pm 3.1$ & $8.3 \pm 0.5$ & $9.0 \pm 0.8$ & $7.3 \pm 0.6$ & $7.5 \pm 0.6$ \\
\hline$\Delta \%$ & $-37.1 \pm 21.3$ & $-24.2 \pm 4.5$ & $-41.5 \pm 15.0$ & $-48.2 \pm 8.9$ & $-6.4 \pm 3.3$ & $-8.2 \pm 7.0$ \\
\hline
\end{tabular}

Values are presented as mean \pm standard deviation.

$\mathrm{VE}$, values of ventilation; $\mathrm{VO}_{2 \max }$, maximal oxygen uptake; $\mathrm{HR}$, heart rate; $\mathrm{O}_{2}$ pulse, $\mathrm{VO}_{2} / \mathrm{HR}$.

${ }^{*} P<0.05$, independent $t$-test.

\section{Statistical analysis}

For data analysis, an independent $t$-test was used for comparison of average changes among the groups. To indicate the recovery rate for each recovery timing, $\Delta \%=[($ after change-before change $) /$ before change $\times 100]$ was calculated and written. The statistical significance for all statistics was tested using IBM SPSS Statistics ver. 21.0 (IBM Co., Armonk, NY, USA) at a level of $P=0.05$.

\section{RESULTS}

The time of reaching the $\mathrm{VT}\left(\mathrm{R}_{\mathrm{vt}}\right)$ was shown to be significantly higher $(P=0.04)$ in the nonsmoker group compared to the smoker group. There were no significant differences in the $\mathrm{VE}_{\mathrm{vv}}, \mathrm{VO}_{2 \mathrm{vt}}$, and $\mathrm{HR}_{\mathrm{vv}}$. There were also no significant differences between the groups at the time of maximum exercise (Table 2).

The HR during recovery 1 and 3 min after maximum exercise were significantly lower in the nonsmoker group compared to the smoker group $(P=0.02$ and $P=0.01$, respectively). However, no significant difference was observed at $5 \mathrm{~min}$ into recovery. There were no differences shown in $\mathrm{VE}, \mathrm{VO}_{2 \max }$, and $\mathrm{O}_{2}$ pulse (Table 3).

\section{DISCUSSION}

Typically, the metabolic rate increases by about 20 times, cardiac output by at least 6 times, and ventilation by about 16-30 times during exercise compared to those in a resting condition. Such reaction differs based on the patient's age, sex, and fitness and the type of exercise. The gas exchange and metabolic rate increase usually occurs due to the interaction between cardio vascular relation and the respiratory system. Chronic smokers' airway resistance during intense exercise is higher by 2 times or more com- pared to nonsmokers, and the oxygen transport ability of habitual smokers also decreases by $10 \%$.

Smoking lowers the blood hemoglobin's oxygen transport ability and stimulates the veins in the airway, which increases mucus secretion, causing a decline in lung functions. Individuals with great fitness often have higher ventilatory or anaerobic thresholds, which shows that the energy metabolic system within the cells using oxygen is healthier (Brooks et al., 2005). This study's result showed that the nonsmoker group's Rvt was significantly higher than in the smoker group. This means that the ventilation's timing of fatigue accumulation is more delayed than in the smoker group, and exercise adherence is easier.

Cardiopulmonary function is the ability for circulation and respiratory functions to increase proportionately to exercise intensity. Having individuals perform maximum exercise and directly measuring the $\mathrm{VO}_{2}$ is a gold standard for evaluating their cardiorespiratory fitness or exercise ability (ACSM, 2010). The results of this study showed no significant differences between the groups for $\mathrm{VE}_{\max }, \mathrm{VO}_{2 \max }$, metabolic equivalent, $\mathrm{HR}_{\max }, \mathrm{O}_{2}$ pulse, and total exercise time. This seems to be due to regular trainings, young body age, and short period of smoking. However, Knapik et al. (1993) stated that young male smokers have a lower $\mathrm{VO}_{2 \max }$ amounts compared to nonsmokers, and smoking not only increases secretion of mucus but also suppresses its discharge. In the study of Macera et al. (2011), comparison of fitness based on smoking and nonsmoking in navy officers who perform regular trainings showed that smokers have a more delayed duration in finishing a running course of the same distance. As reported by many such preceding studies, athletes who regularly train face the risk of negative impact on their endurance exercise ability and cardiopulmonary function if their period of smoking becomes longer. 
Postexercise HR recovery is a good indicator of the ability of the respiratory circulation system. Sports athletes are known to have fast HR recovery after maximum exercise. Reports show a fast decline for 1 and 2 min after maximum exercise while, after 3 min, the decline is slower (Myers et al., 2002; Kim et al., 2014). The results of this study showed that the nonsmoker group has a significantly higher HR recovery rate at $1 \mathrm{~min}$ and until $3 \mathrm{~min}$ compared to the smoker group. The smoker group's higher HR during recovery after maximum exercise indicates that the oxygen consumption of the heart muscles has increased, leading to increasing burden on the heart, potentially lowering exercise ability. Thus, smoking can act as one of the factors hindering cardiopulmonary function recovery. The study of Imai et al. (1994) also reported that nonsmoking, healthy individuals and well-trained athletes have a fast HR recovery rate, showing a similar tendency with this study.

The $\mathrm{O}_{2}$ pulse during maximum exercise is the value of oxygen consumption divided by HR and means the level of oxygen supply from 1 heartbeat; it is used as an indicator of cardiovascular efficiency. $\mathrm{O}_{2}$ pulse is related to the arteriovenous oxygen difference in the arterial and venous bloods along with cardiac output and, thus, can indirectly evaluate the oxygen amount extracted from the peripheral tissues (Wasserman et al., 1967). This study's results showed no significant difference in the $\mathrm{O}_{2}$ pulse during recovery. This seems to result from the lack of significant difference in respiratory factors such as $\mathrm{VE}$ and $\mathrm{VO}_{2 \max }$.

The results of this study showed that the nonsmoker group's $R_{v t}$ and $\mathrm{HR}$ recovery rate at 1 and 3 min of recovery were significantly higher than in the smoker group. This shows that it is easy to improve exercise adherence and athletic performance from the ventilation's higher fatigue accumulation timing and fast recovery after exercise. Smoking has more negative impact on cardiopulmonary function when the amount of smoking is greater and the period is longer (Gold et al., 1996). However, stopping smoking can bring improvement in lung functions, and structural changes and lung function impairments from smoking can be averted to a certain extent at an early stage (Macklem, 1972). Therefore, athletes should stop smoking as soon as possible for improvement of cardiopulmonary function and athletic performance in addition to their own health.

\section{CONFLICT OF INTEREST}

No potential conflict of interest relevant to this article was reported.

\section{ACKNOWLEDGMENTS}

This research was supported by the Ministry of Trade, Industry and Energy (MOTIE), KOREA, through the Education program for Creative and Industrial Convergence (grant number: N0000717).

\section{REFERENCES}

American College of Sports Medicine. ACSM's guidelines for exercise testing and prescription. 8th ed. Philadelphia (PA): Lippincott Williams \& Wilkins; 2010.

Anton MM, Cortez-Cooper MY, DeVan AE, Neidre DB, Cook JN, Tanaka $\mathrm{H}$. Cigarette smoking, regular exercise, and peripheral blood flow. Atherosclerosis 2006;185:201-205.

Brooks GA, Fahey TD, Baldwin KM. Exercise physiology. Human bioenergetics and its application. 4th ed. Boston: McGraw-Hill, 2005.

Dogan A, Yarlioglues M, Gul I, Kaya MG, Ozdogru I, Kalay N, Inanc MT, Ozdogru M, Ardic I, Dogdu O, Eryol NK, Ergin A, Oguzhan A. Acute effects of passive smoking on left ventricular systolic and diastolic function in healthy volunteers. J Am Soc Echocardiogr 2011;24:185-191.

Gold DR, Wang X, Wypij D, Speizer FE, Ware JH, Dockery DW. Effects of cigarette smoking on lung function in adolescent boys and girls. $\mathrm{N}$ Engl J Med 1996;335:931-937.

Grover RF, Weil JV, Reeves JT. Cardiovascular adaptation to exercise at high altitude. Exerc Sport Sci Rev 1986;14:269-302.

Halliwill JR, Minson CT. Effect of hypoxia on arterial baroreflex control of heart rate and muscle sympathetic nerve activity in humans. J Appl Physiol (1985) 2002;93:857-864.

Imai K, Sato H, Hori M, Kusuoka H, Ozaki H, Yokoyama H, Takeda H, Inoue M, Kamada T. Vagally mediated heart rate recovery after exercise is accelerated in athletes but blunted in patients with chronic heart failure. J Am Coll Cardiol 1994;24:1529-1535.

Kim DY, Seo BD, Choi PA. Influence of taekwondo as security martial arts training on anaerobic threshold, cardiorespiratory fitness, and blood lactate recovery. J Phys Ther Sci 2014;26:471-474.

Knapik J, Zoltick J, Rottner HC, Phillips J, Bielenda C, Jones B, Drews F. Relationships between self-reported physical activity and physical fitness in active men. Am J Prev Med 1993;9:203-208.

Macera CA, Aralis HJ, Macgregor AJ, Rauh MJ, Han PP, Galarneau MR. Cigarette smoking, body mass index, and physical fitness changes among male navy personnel. Nicotine Tob Res 2011;13:965-971.

Macklem PT. Obstruction in small airways: a challenge to medicine. Am J Med 1972;52:721-724.

Myers J, Prakash M, Froelicher V, Do D, Partington S, Atwood JE. Exercise capacity and mortality among men referred for exercise testing. $\mathrm{N}$ 
Engl J Med 2002;346:793-801.

Seo B, Kim D, Choi D, Kwon C, Shin H. The effect of electrical stimulation on blood lactate after anaerobic muscle fatigue induced in Taekwondo athletes. J Phys Ther Sci 2011;23:271-275.

Tantisuwat A, Thaveeratitham P. Effects of smoking on chest expansion, lung function, and respiratory muscle strength of youths. J Phys Ther Sci 2014;26:167-170.

Wasserman K, Van Kessel AL, Burton GG. Interaction of physiological mechanisms during exercise. J Appl Physiol 1967;22:71-85.

Willemse BW, Postma DS, Timens W, ten Hacken NH. The impact of smoking cessation on respiratory symptoms, lung function, airway hyperresponsiveness and inflammation. Eur Respir J 2004;23:464-476.

World Health Organization. The World Health report: life in the 21st century a vision for all. Geneva (Switzerland): World Health Organization; 1998. 